\title{
Numerical investigations of Stilt houses natural ventilation and Thermal Comfort Evaluation in Southern Yunnan Province
}

\author{
Zhiyong Zhou ${ }^{1, a}$, Xin Zhong ${ }^{2, b}$ and Zhuowei Duan ${ }^{3, c}$ \\ ${ }^{1,2}$ College of Architecture and Civil Engineering, Kunming University of Science and Technology, \\ Kunming, China \\ ${ }^{3}$ Kunming Architectural Design \& Research Institute, Kunming, China \\ azhiy_zhou@163.com, ${ }^{\text {b4 } 489434879 @ q q . c o m, ~}$
}

Keywords:Stilt houses; Natural ventilation; Thermal comfort evaluation;Optimization schemes Abstract.For the purpose of improving the effect of natural ventilation and thermal comfort of a traditional stilt houseslocated inSouthern Yunnan Province. Theindoor and outdoor windenvironment of the existingStilt houseswere simulated by Airparksoftware, thefactors of indoor ventilation effect and thermal comfort were analyzed,and the effects of the sizeand location of the windows and vents on natural ventilation were analyzed.The results indicated thatthe size and location of the windowscould improve the indoor natural ventilation effectandthe indoor air temperaturereduced of $2.4^{\circ} \mathrm{C}$ in summer,while the role of the vent is not obvious. Furthermore,the design suggestions and strategiesfor enhancing the thermal comfortof a traditional stilt houselocated in theSouthern Yunnan Provincewere presented.

\section{Introduction}

In recent years, along with strengthening ofenergy saving and environmental protection awareness, Architects paidmore attention to the role of natural ventilation in saving building energy, a lot of scholars had also done related research of natural ventilation.

Potential of natural ventilation in temperatecountrieswas proved to be enormous; there was a reduction of $90 \%$ of hours of a possible use of mechanical ventilation ${ }^{[1]}$. By using CFD software to simulate a typical architecture of Thailand, the resultsindicated thatapproximately $2700 \mathrm{kWh}$ of air conditioning energy savings could be achieved in the room by employing the proposed ventilation shaft ${ }^{[2]}$. The natural ventilation effect and thermal comfort of atrium buildings hadalso beenwidely researched ${ }^{[3-5]}$. Therewas a lot of research about the influence of building orientation, shape coefficient, opening size and locationon indoor ventilation effect, and many new methods have been proposed to optimize ventilation ${ }^{[6-8]}$. Studies was shown that rational setup of courtyards'size and walls'heightcould increase the natural ventilation effect of courtyards ${ }^{[9]}$. But the above researches were not involved in the natural ventilation of theStilt houses.

Stilt houses-i.e. housesraised on piles over the surface of the soil or a body of water. Stilt houses were built primarily as a protection against flooding, but also served to keep out vermin. The shady space under the house could be used for work or storage ${ }^{[10]}$. Thehouses weremade of bamboo and thatch andincluded one or two fireplace. Thefireplaces were usually used to cook the meals, and it also was the traditional customs of the local residents.

\section{CFD Simulation}

\subsection{Simulation Methods}

In this paper, theindoor and outdoor wind environments of the Stilt houses weresimulated by the CFD software.the simulation weredivided into two parts: Firstly, the outdoor modelwere established to researchthe wind field around buildings; Secondly, the indoor modelwere establishedbased on the simulation results of the outdoor model to research the indoor air temperature, relative humidityand wind speed. 


\subsection{CFD Model}

\subsubsection{Outdoor Model}

The computational domainshown in Fig. 1 was $130 \mathrm{~m}(\mathrm{~L}) \times 60 \mathrm{~m}(\mathrm{~W}) \times 28 \mathrm{~m}(\mathrm{H})$, the discretization grid consists of 625.3thousandhexahedralcells.TheRNG $\kappa$-emodel and discrete ordinated rendition model wereused in the model.Theinflowboundarywasgradient wind, the wind speed was $2.4 \mathrm{~m} / \mathrm{s}$ and the direction was North East whichbased on the local weather data.The outflow boundarywas zero static pressure.At the ground and building surfaces, the standard wall functions were used in conjunction with thesand-grain based roughness modification. The lateral side of the domain was symmetry boundarycondition.

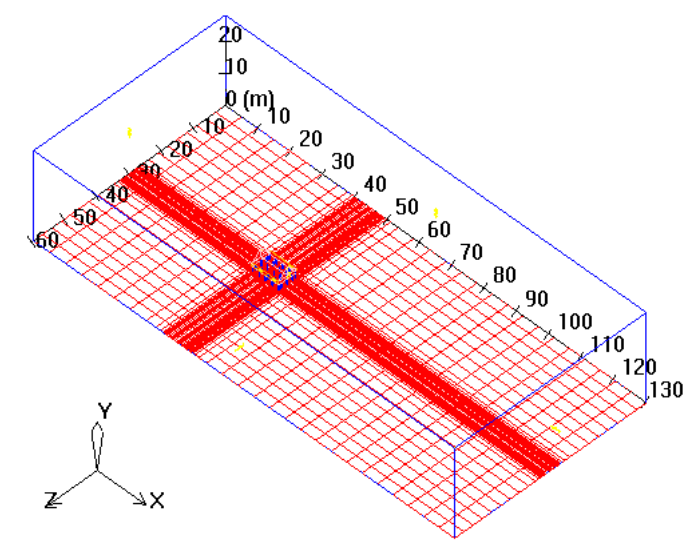

Fig.1outdoor model

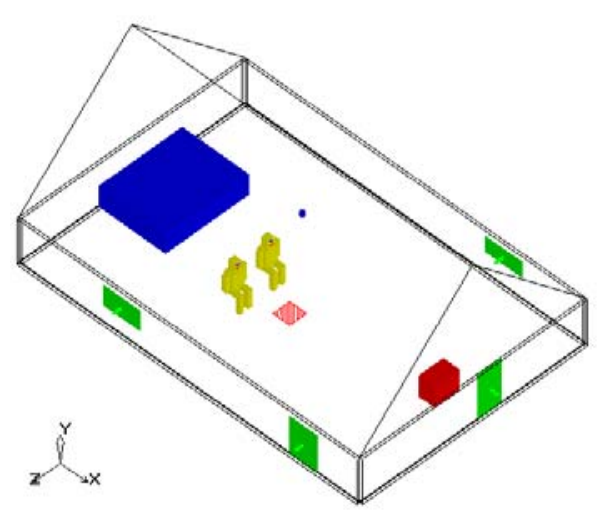

Fig.2 Indoor model

\subsubsection{Indoor Model}

The computational domainof indoor model is the interior space surrounded by building envelope, the size is $8.15 \quad(\mathrm{~L}) \times 5.4 \quad(\mathrm{~W}) \times 5.6 \quad(\mathrm{H}) \mathrm{m}^{3}$ (shown in fig.2). The "velocity inlet"boundarywastemperature of $28.6^{\circ} \mathrm{C}$, relative humidity of $66 \%$. For the outlet of the flow, the "pressure outlet" was taken. The wall temperatureswasbased on , thethermalparameters of other heat sources were shown inTab1.According to the calculation results of outdoor model, the inlet and outlet boundary wereshown in Table2.

Tab1. Thermalparameters of internal thermal loads

\begin{tabular}{|l|c|}
\hline Internal heat source & \\
\hline Person $\left(\mathrm{W} / \mathrm{m}^{2}\right)$ & $58 \times 2$ \\
\hline Lamp $\left(\mathrm{W} / \mathrm{m}^{2}\right)$ & 34 \\
\hline Television $\left(\mathrm{W} / \mathrm{m}^{2}\right)$ & 120 \\
\hline Fireplace $\left({ }^{\circ} \mathrm{C}\right)$ & 600 \\
\hline
\end{tabular}

Tab2. Boundary conditions of inlet and outlet of indoor model

\begin{tabular}{|l|c|c|c|c|}
\hline & North window & South window & South Gate & East gate \\
\hline average wind pressure $(\mathrm{Pa})$ & 0.872 & -0.662 & -0.551 & 0.512 \\
\hline
\end{tabular}

\subsection{Simulation Results Analysis}

Thesimulation results of outdoor model were shownin Fig.3 and 4, the averagebuilding surfacepressure of windward and leeward was $0.465 \mathrm{~Pa}$ and $-0.619 \mathrm{~Pa}$. Theaveragewind speed around the building is $0.351 \mathrm{~m} / \mathrm{s}$. The results showed that the outdoor wind environment was adverse for indoor natural ventilation. 

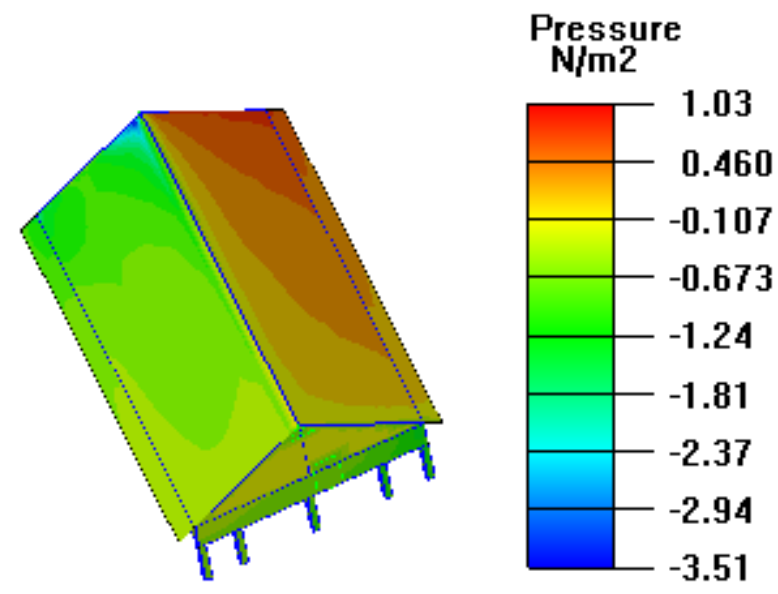

Fig.3Building surface pressure

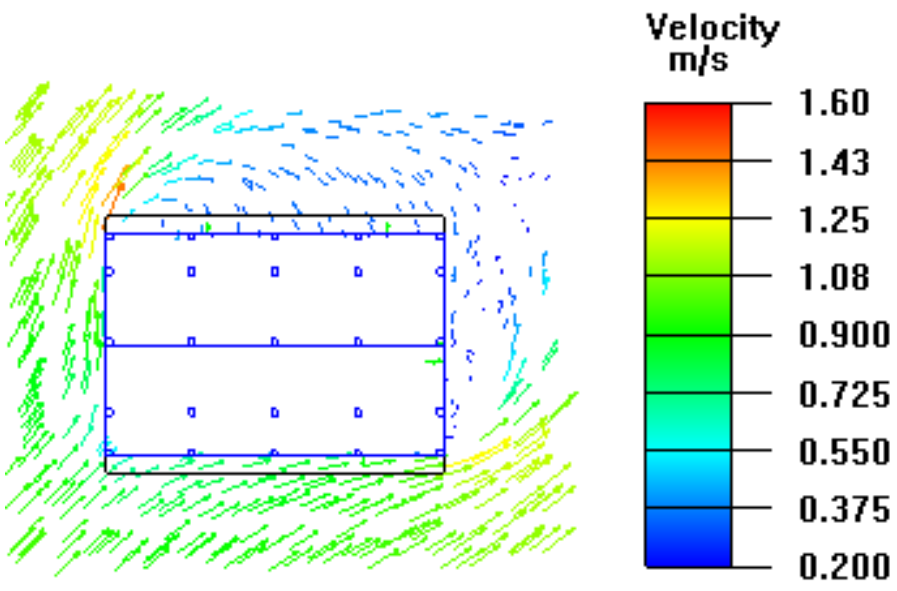

Fig.4Velocity vectors of the outdoor model

The simulation results of indoor model were shown in Fig.5 and 6. It showed that theair velocitynear the windowswaslarger, while the air velocity of other regionwas small or even clam. The average velocity and temperature of the indoor region at $1.2 \mathrm{~m}$ above the floor was $0.11 \mathrm{~m} / \mathrm{s}$ and $31.1^{\circ} \mathrm{C}$, respectively.
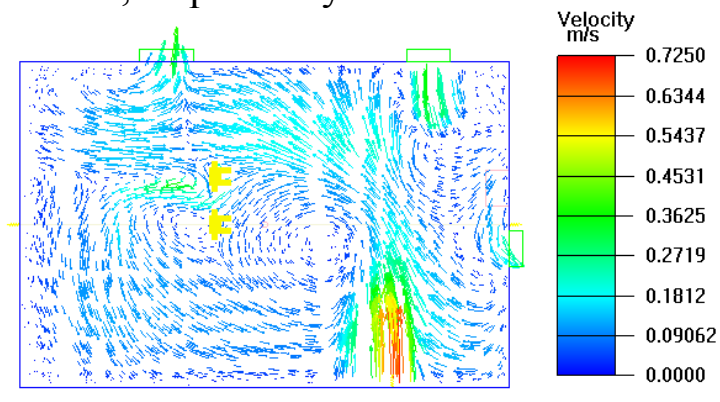

Fig.5velocity vectors of the indoor $\operatorname{model}(\mathrm{z}=1.2)$

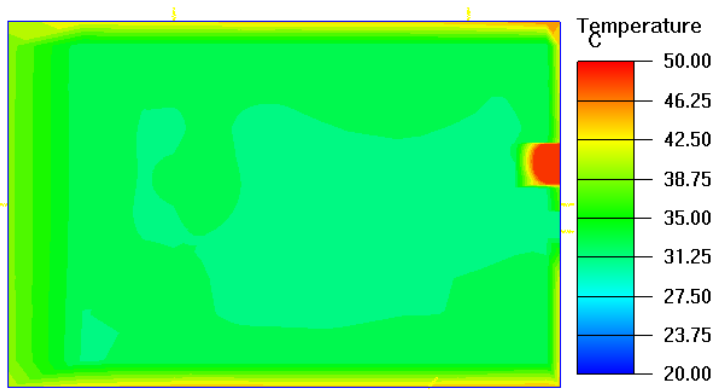

Fig.6Temperature contours of the indoor $\operatorname{model}(\mathrm{z}=1.2)$

\section{Optimization Schemes}

There were many factors influenced the effect of indoor ventilation and thermal environment, such as orientation, shape coefficient, opening size and location, etc...But only the opening size and locationwere analyzedand the other factor was defaultin this paper.Then three optimization schemeswere put forward based on the mechanism of natural ventilation. Details are shown in Table3.

In caseA,cross-ventilationwouldappear when the outdoor wind speed wasfavorable, while the effect of buoyancy-driven natural ventilationcouldnot be considered. In case $B$, the buoyancy-driven natural ventilation wasconsidered, whilethe cross-ventilation wasadverse.In case C, thewind pressureand buoyancy-drivennatural ventilation was taken into the model.

Table3Optimization scheme of ventilation

\begin{tabular}{|c|l|}
\hline Case & \multicolumn{1}{c|}{ Optimization measures } \\
\hline Case A & $\begin{array}{l}\text { Add a windowon the south and north wall respectively,thesize of window is } 0.9 \times \\
0.6 \mathrm{~m}^{2} ; \text { add two Windows on the south and north side roof respectively, thesize of } \\
\text { window is } 0.6 \times 0.45 \mathrm{~m}^{2}\end{array}$ \\
\hline Case B & Add four vents on the floor, size is $0.6 \times 0.4 \mathrm{~m}^{2}$ \\
\hline Case C & $\begin{array}{l}\text { Add a window on the south and north wall respectively,thesize of window is } 0.9 \times \\
0.6 \mathrm{~m}^{2} ; \text { Add two Windows on the south and north side roof respectively, thesize of } \\
\text { window is } 0.6 \times 0.45 \mathrm{~m}^{2} \text {;Add four vents on the floor, size is } 0.6 \times 0.4 \mathrm{~m}^{2}\end{array}$ \\
\hline
\end{tabular}

\section{Results and discussions}

Theaccurateopeningboundary conditions of each modelwereobtained by using the CFD software to 
simulate the outdoor wind environment of each case. According to the simulation results, the wind speedand wind pressure of each opening as theboundary conditions of the indoor wind environmentsimulationare obtained while the conditionsof all internalthermalloadsweredefault. The simulation results of average wind speed and air temperaturewere shown in Fig. 7 and 8.

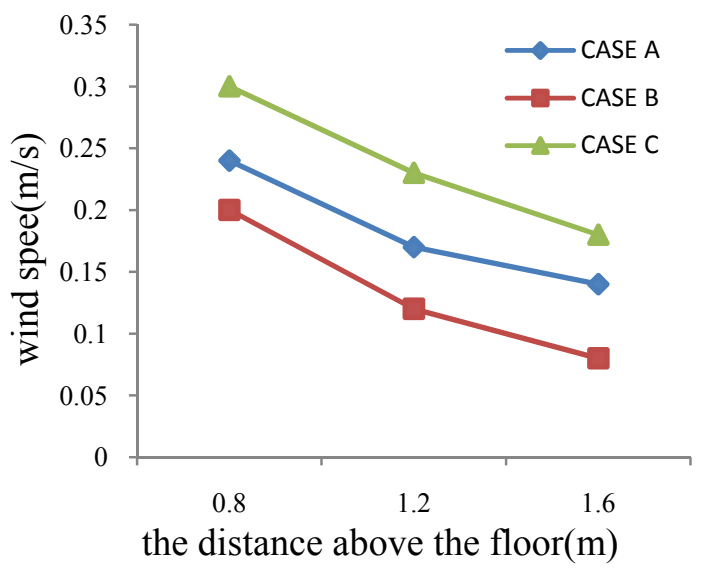

Fig.7 average win speed of each case

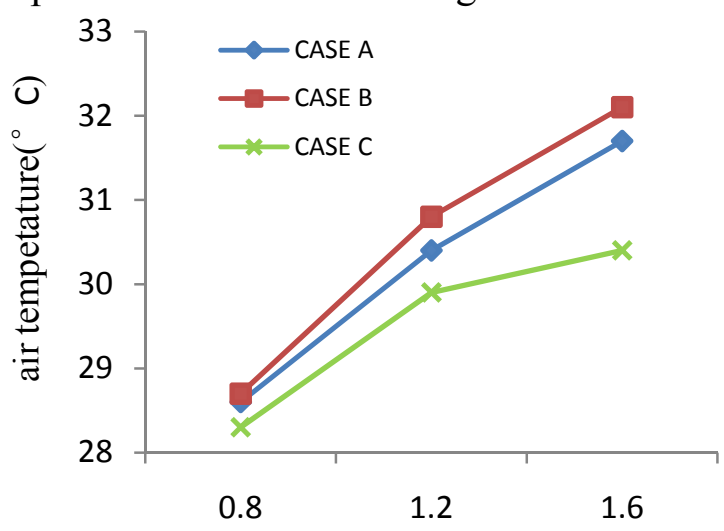

the distance above the floor $(\mathrm{m})$

It could be seen from Fig. 7 and 8 that thewind speed of the case Cwas large,followed by caseA, and the case $\mathrm{B}$ is minimal.The reason was that the role of buoyancy-drivennatural ventilation waslittlewhen the temperature variations between the indoor and outdoor environment was small.

The comparison of the effect of indoor ventilation and thermal comfort of case $\mathrm{A}$ and $\mathrm{C}$ wasshown in Fig.9.it can be seenthat the CFD predictions of the indoor air velocityof case C was better than case $\mathrm{A}$, and at the same time the calm windarea of case Cwassmaller than case A.The vertical air temperature difference of $3^{\circ} \mathrm{Cis}$ recommend in ISO7730 standard, while the vertical air temperature difference of case $\mathrm{A}$ is $3.2^{\circ} \mathrm{C}$ which beyond the standard recommended values. Therefore, from the angle of thermal comfort, the Case $\mathrm{C}$ was the best optimization scheme.

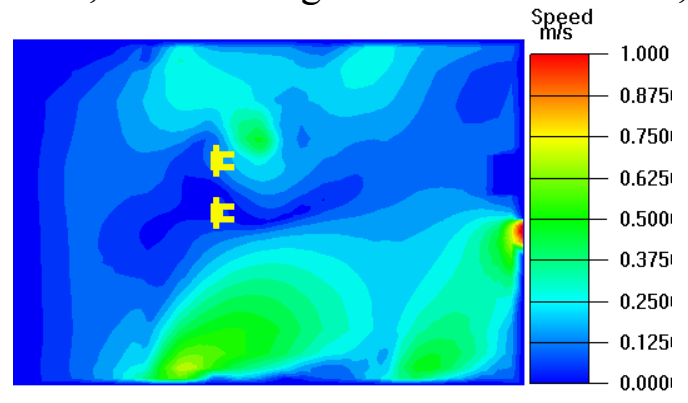

Fig.9-a velocity contours of caase $\mathrm{A}(\mathrm{z}=1.2)$

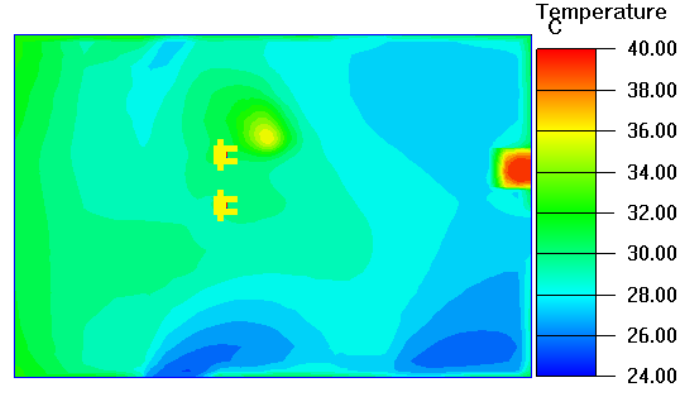

Fig.9-c Temperature contours of case $\mathrm{A}(\mathrm{z}=1.2)$

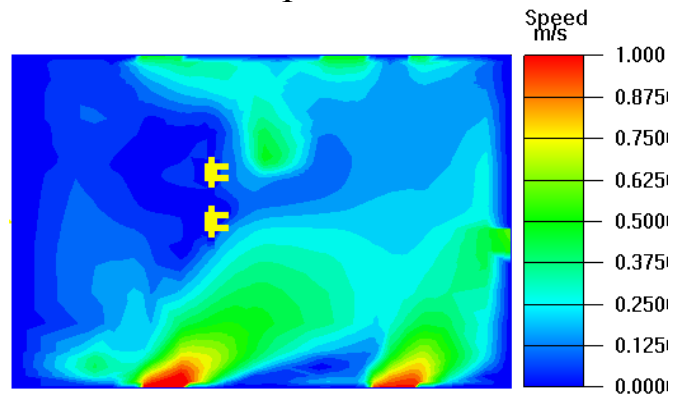

Fig.9-b velocity contours of caase $\mathrm{C}(\mathrm{z}=1.2)$ Temperature

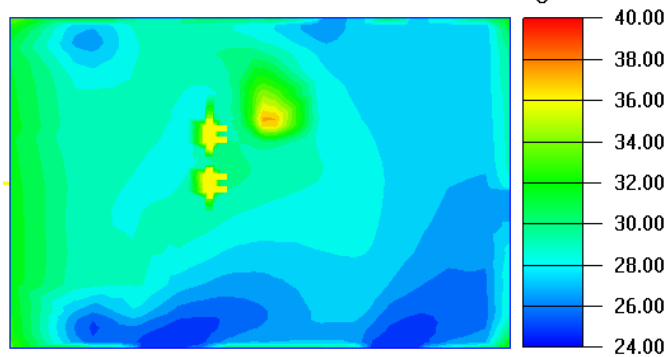

Fig.9-d Temperature contours of case $\mathrm{C}(\mathrm{z}=1.2)$

\section{Conclusions}

In this study, a traditional stilt houseswas modeled and the effect of cross-ventilation and buoyancy-driven natural ventilation is investigatedusing a validated CFD model.Steady-state CFDsimulations of the natural ventilation airflowand temperature distributions in the building were carried out utilizing the RNG $\kappa-\varepsilon$ turbulence model. Furthermore, three optimization schemes were put forward and simulated in terms of the mechanism of natural ventilation. The following main 
conclusions weredrawn from this study.

1. From the analysis of the results obtained for various optimization schemes, it was found thatthe cross-ventilationstrategywasfavorable to improvethe effrct of natural ventilationin hot summer, but the effect of natural ventilation was adverse when only used the buoyancy-driven natural ventilation.

2.It wasobserved thatthe Case $\mathrm{C}$ was the best optimization scheme as the effect of cross-ventilationandbuoyancy-driven natural ventilationwere takenaccount into this model.This case was effective to improve the indoor ventilation effect and thermal environment with the velocity of airincreased by 1.95 times and the temperature reduced of $2.4^{\circ} \mathrm{C}$.

3. Overall,the results indicated thatrationally setting the size and location of the windows and vents could improve the indoor natural ventilation effect in hot summer,the relative location of openings shouldmake full use of the effect of cross-ventilationandbuoyancy-driven natural ventilation.

\section{Acknowledgements}

This work was financially supported by:

(1) National Natural Science Foundation of China, under Grant No.51268020.

(2) Key Projects in the National Science \& Technology Pillar Program, under Grant No.2013 BAJ07B01.

\section{References}

[1]Ivan Oropeza-Perez,Poul Alberg Østergaard. Potential of natural ventilation in temperatecountries - A case study of Denmark[J].Applied Energy,2014,114:520-530.

[2]PimolsiriPrajongsan, Steve Sharples.Enhancing natural ventilation, thermal comfort and energy savings in high-riseresidential buildings in Bangkok through the use of ventilation shafts[J].Building and Environment, 2012, 50:104-113.

[3]Shafqat Hussain, Patrick H. Oosthuizen.Numerical investigations of buoyancy-driven natural ventilation in a simpleatrium building and its effect on the thermal comfort conditions[J].Applied Thermal Engineering,2012,40:358 372.

[4]Shafqat Hussain, Patrick H. Oosthuizen.Numerical study of buoyancy-driven natural ventilationin a simple three-storey atrium building[J].International Journal of Sustainable Built Environment,2012,1:141-157.

[5]Leila Moosavi, Norhayati Mahyuddin,Norafida Ab Ghafar. Thermal performance of atria:An overview of natural ventilation effectivedesigns[J].RenewableandSustainableEnergyReviews, 2014,34:654-670.

[6]Chia-Ren Chu,Bo-Fan Chiang.Wind-driven cross ventilation in long buildings.Building and Environment,2014,80:150-158.

[7]John Kaiser Calautit, Ben Richard Hughes.Wind tunnel and CFD study of the naturalventilation performance of a commercial multi-directional wind tower.Building and Environment,2014,80:71-83.

[8] J.I. Perén, T. van Hooff, B.C.C. Leite, B. Blocken.CFD analysis of cross-ventilation of a generic isolated building withasymmetric opening positions: Impact of roof angle and openinglocation.Building and Environment, 2014,85:263-276.

[9]Liang Wang, Jun Lu, Juanzha.Analysis of the impact of window opening mode on the effect of indoor natural ventilation.Journal of chongqing university,2011,34:75-79.

[10]David M. Bush. Living with Florida's Atlantic beaches: coastal hazards from Amelia Island to Key West[B]. Duke University Press. page263-264. 